\title{
LITERATURA FEMENINA EN MEXICO \\ EN LA ANTESALA DEL AÑO 2000 \\ (Antecedentes: Siglos XIX y XX)
}

POR

\author{
MARGARITA PEÑA \\ Universidad Nacional Autónoma de México
}

A lo largo de cinco siglos de cultura, la escritura femenina - la litcratura cscrita por mujeres - ha ido ganando un sitio que en los primeros siglos de la dominación cspañola - XVI y XVII- fuc precaria, y en el XX, cn cambio, sc halla plenamente consolidada, es exultantemente representativa. Los siglos XVIII y $X I X$ se configuraron como épocas en las que, a parlir de un balbucco incipiente $c$ incvitable, la litcratura femenina transitó de los certåmenes poéticos a los salones decimonónicos, en los cuales la mujer desempeñó alternativamente los papeles de autora y musa. Ya Sor Juana Inés de la Cruz se crige como figura única, auténtico "fénix de los ingenios", en la segunda mitad del XVII, fenómeno litcrario comparable, cn cuanto a calidad y variedad de su obra, a un Félix Lope de Vega, o a un Pedro Calderón de la Barca. Solitaria en lo que parecería ser un mundo vacio respecto a lo específicamente femenino, Sor Juana constituye el epicentro de una secuencia literaria colonial de escritoras que apenas ahora se empicza a descubrir, a cstablecer. El siglo XX rebosa, cn cambio, de mujeres que en plena afirmación de su identidad creadora, escriben cuento, poesía, novela, teatro y ensayo. Pero vayamos por paries.

Desde los primeros momentos de la colonización, a partir del año 1951, cuando Tenochtitlán cae en poder de los españoles, la Nueva España recibe, junto con una humanidad heterogénea, las modas que triunfan en la metrópoli. Paralclamente llegan los libros, $\mathrm{y}$ los españoles y primcros criollos avecindados $\mathrm{cn}$ la capital, en Puebla o en Guadalajara leen — como los habitantes de Toledo, de Cucnca o de Scvilla - la pocsía de influencia italianizante, el soncto, o la canción al modo petrarquista. Es posible que un día no muy lejano se localice la obra de cscritores del XVI en archivos, en bibliotecas privadas (que suclen guardar verdaderos tesoros bibliográficos) o en acervos de provincia. Si los cronistas mencionan a personajes femeninos que participaron en la conquista -Beatriz Hernández, mujer de Juan Sánchez de Olca, citada por fray Antonio Tello en su Crónica de Nueva Galicia, quien, llegado el momento, capitaneó a las mujeres que 
seguian a los conquistadores; si sabemos de tempranas fundadoras de conventos, como Isabel de Gucvara, nicta del conquistador Andrés Barrios, la que en 1580 funda el convento de San Jerónimo, ipor qué dudar que entre una población a medias alfabetizada, a medias culta, hayan existido mujeres - pocas, quizás-que detentaran el privilegio de saber lecr y escribir y se dieran a la tarea de pergeñar décimas, coplas o sonctos, ya sagrados, ya profanos? El gran tclón de fondo que cnmarca a los autores conocidos - Sor Juana, Sigüenza y Góngora, Juan Ruiz de Alarcón- se configura apenas y hay que prepararse para las sorpresas que la investigación depare.

Tomando como antecedente inmediato y obligado del desbordante siglo XX, cl curopeizante XIX, cncontramos que en esic siglo, marcado ya por la influencia litcraria francesa, inglesa y alcmana, las cscritoras son tocadas, al igual que los hombres, por el "mal du siècle" del romanticismo. Isabel Prieto de Landázuri (1833-1876), nacida en España, arribó a México de corta edad, aquí se formó y llegó a escribir pocsía y teatro, y a traducir autores europeos que, a un tiempo, se configuraron como sus presencias tutclares. Al igual que las autoras de siglos antcriores, altcrnó con escritores en lo que en el XIX se llamaba "socicdades litcrarias". Su pocsía fuc recogida por José María Vigil con cl título de Obras poéticas coleccionadas y precedidas de un estudio biográfico y literario (México, 1883). El tratamiento de los problemas femeninos, en una tesitura romántica, la emparcja con otra excelente escritora del XIX, la cubana Gertrudis Gómez de Avcllaneda, aun cuando algunos de los títulos de su teatro (La escuela de las niñas) nos traigan más bien reminiscencias cspañolas neoclásicas, costumbristas, de los dos Moratín, padre $\mathrm{c}$ hijo, y nos remilan asimismo a su contemporảnco, $\mathrm{cl}$ dramaturgo mexicano Fernando Calderón. Se la llegó a considerar la primera romăntica de nuestra recién liberada Nueva España, ya para entonces conocida como México. Otras escritoras del XIX scrán Dolores Correa Zapata, Laura Méndez de Cuenca, Teresa Farias de Isassi, María Luisa Ross, Laura Wright de Kleinhans.

Josefa Murillo (1860-1898), autodidacta precoz, scrá cjemplo de una vida, una sensibilidad y una pocsía románticas que se corresponden y se entrelazan. Imposibilitada para estudiar, leyó por su cucnta infatigablemente; enamorada de un hombre que murió sin desposarla, se dice que clla, antes de morir pidió que colocaran en su féretro las cartas escrilas por el amado. Vivió siempre en Tlacotalpan, Veracruz, y su obra quedó dispersa en publicaciones locales. Sin cmbargo, Luis G. Urbina, el gran conocedor decimonónico de la pocsía femenina, y José María Vigil, le otorgaron, en su momento, admiración y respeto. Sc conserva algún álbum manuscrito, $\mathrm{en} \mathrm{cl} \mathrm{que} \mathrm{alternan} \mathrm{poemas} \mathrm{con} \mathrm{ilustraciones} \mathrm{que}$ clla misma claboró. En cl terreno de la prosa, otra mujer dotada, como la Murillo, 
de gran voluntad para instruirse y escribir, fue María Néstora Téllez Rendón (18291890). A pesar de haber perdido totalmente la vista, pudo adquirir una amplia cultura, y llegó a dirigir una escuela en Michoacán. Es evidente que la secularización de las costumbres, lograđa a raiz del movimiento de Independencia, permitió a las mujeres acceder a estados que no fucran sólo el religioso o cl del matrimonio. Posecdora María Néstora Téllez de una sensibilidad tendiente a la mística, concibió una novela, Staurófila, en la que trata de los amores del alma con Dios. Hasta donde se sabe, la obra alcanzó ocho ediciones, fue libro de cabecera de varias generaciones de lectoras, y parece continuar la secuencia de una literatura de tono místico que había surgido, y llegado a proliferar, en los siglos anteriores.

$\mathrm{Se}$ inaugura el siglo XX con el movimiento revolucionario, y tanto $\mathrm{cl}$ buen nivel de la educación como la nueva conciencia social serán factores que coadyuven a la expansión de la litcratura femenina. En cl contexto poético, Concha Urquiza (1910-1945) expone, a lo largo de sus Obras, una poesía de tendencia introspectiva, fucrtemente mística, de calidad indudable. Emma Godoy (1918), con una sólida formación filosófica y teológica, hace dos tipos de literatura que se complementan: pocsía crótica en Pausas y arena, y prosa de reflexión en torno a la condición humana en Erase una hombre pentafácico. Griselda Alvarez (1918), inclinada tanto a la literatura como a la política (fue gobernadora del Estado de Colima), cucnta con una obra relcvante: Cementerio de pájaros, Dos cantos, Desierta compañía, Letanía erótica para la paz.

Guadalupe ("Pita") Amor (1920) es quizás la poctisa más controvertida de las que nacicron en el primer tercio del siglo XX. Autora de una extensa producción (Yo soy mi casa, Puerta obstinada, Círculo de angustia, Polvo, Más allá de lo oscuro, Décimas a Dios, Otro libro de amor, Sirviéndole a Dios en la hoguera, Todos los siglos del mundo), incursiona también en la novela y cl relato (Yo soy mi casa, novela; Galeria de títeres, relatos). Sus formas poćticas predilcctas son cl soncto (alguno tan logrado como los de los "Contemporáneos" Salvador Novo o Javier Villaurrutia) y la décima. Sus temas: el diálogo angustiado con Dios, cl desgarrado sentimiento amoroso, la caducidad de la vida. Su tesitura permanente: la duda, la interrogación. Mujer de gran intensidad sensitiva y pasional, su particular forma de gozar y sufrir el mundo quedan plasmados en los rímicos versos de vívido registro confesional. A Yo soy mi casa pertenece el fragmento siguicnte:

Yo soy cóncava y convexa; dos medios mundos a un tiempo: el turbio que muestro afuera, y el mío que llevo dentro. 


\begin{abstract}
Son mis dos curvas mitades tan auténticas en mí, que a hondur as y liviandades toda mi esencia les dí. Yen forma tal conviví con negro y blanco exiremoso, que a un mismo tiempo aprendí infiemo y cielo tortuosos.
\end{abstract}

La producción poética de Guadalupe Amor, vertida en libros o en pocmas sucltos, pese a lagunas incvitables, cubre las cuatro décadas que van de 1947, en que aparcció Yo soy mi casa, a 1987.

Margarita Michelena (1917), combina la litcratura con el periodismo. Poscedora de vastas lecturas que se transparentan en su excelente mancjo del castcllano, cucnta cntre su producción poćtica Paraíso y nostalagia, Laurel del ángel, Tres poemas y una nota autobiográfica, La tristeza terrestre.

Margarita Paz Paredes (1920-1980), en una tesitura totalmente opuesta a la de Michelena, fusionó en su poesía la nota lírica con la airada protesta social. Publicó mås de quince libros, obtuvo premios diversos y dejó, al morir, una esicla de lectores amigos. Entre sus lílulos figuran Voz de la tierra, El anhelo plural, Retorno, Elegia a Gabriel Ramos Millán, Andamios de sombras, Casa en la niebla, La imagen y su espejo. Es, junto con Guadalupe Amor, la cscritora más prolífica de la gencración de los años veinte.

Enriqueta Ochoa (1928), coahuilense, posec una vocación poćtica que se expresó precozmente, y que se traduce en varias recopilaciones de pocmas: LoS himnos del ciego, Las virgenes terrestres, Retorno de Electra, Bajo el oro pequeño de los trigos.

Dentro de las promociones siguientes hay que mencionar a Carmen Alardín (1933), nacida en Tampico y que actualmente reside en Monterrey, con una obra que aumenta de modo constante: El canto frágil, Pórtico labriego, Celda del viento, Después del sueño, Todo se deja así. A Isabel Fraire (1934), con Poemas en el regazo de la muerte, cntre otros títulos. A Elva Macías (1944), cuyos pocmas sc han incluido cn antologías diversas y entre cuyos libros figuran El paso del que viene, Círculo del sueño, Imagen y semejanza. A Elsa Cross (1946), con La dama de la torre, y, cl más reciente, Baniano. A Coral Bracho: Peces de piel fugaz (pocmas y prosemas); a Verónica Volkow (1955), de scnsibilidad y cxpresión originales, a quien pertenecen las siguientes líneas:

Si se viera amanecer

a la estrella secreta del deseo 
a esa aurora inminente

germinada siempre en la destrucción del fuego ...

Poctisas esparcidas a lo largo de este siglo son la yucateca Dolores Bolio (fines del siglo XIX-1950), autora tambićn de novela y prosa diversa; Aurora Reyes, que nace en 1910, ducña de rica imaginería poćtica; Juana Meléndez de Espinoza (1914); Concha Méndez, cscritora española del cxilio; Olivia Zúniga (1916), pocta prosista; Gloria Riestra (1929): Cena de Amor, Lagar; Norma Bazúa, que ha venido cultivando la pocsía empecinadamente durante las dos últimas décadas. En promociones últimas se inscriben Margarita Dalton, autora de reivindicación social y feminista, Mónica Mansur, y las más jóvenes Gloria Gervitz, Perla Schwartz y Mariana Toussaint.

Antes de pasar adelante, detengámonos en el fenómeno de las revistas literarias dirigidas o sustentadas por mujeres, y de las cuales emergicron "parvadas" de cscritoras. Rueca, cn los años cuarcnta, agrupó cntre otras, a Concha Urquiza, Concha Méndez y María del Carmen Millán, ensayista, crítica y promoŁora litcraria. En la década de los sesenta (1960-1968) se publicó una revista literaria hecha por mujeres: El Rehilete. Colaboradora de ella y animadora de otra revista litcraria, El Pájaro Cascabel, Thelma Nava (1931) se configuró como la poctisa (lel grupo, con composiciones aparecidas tanto en El Rehilete como en recopilaciones diversas: Aqui te guardo yo, La orfandad del sueño, Colibrí 50. Thelma Nava cs una poetisa que, como Paz Paredes, está precocupada, al unísono, por la introspección, la expresión del sentimiento amoroso y la denuncia de tipo social. A la promoción de El Rehilele pertenecen también cuentistas, novclistas y cnsayistas: Beatriz Espejo, autora de La otra hermana, Muros de Azogue (cuentos) y Julio Torri, voyeurista desencantado (cnsayo); Carmen Rosenzweig: El relojy Mi pueblo (relatos); (1956) novela y Volanteo (prosas). Recibió recientemente el premio "Sor Juana Inćs de la Cruz" concedido por el gobicrno del Estado de México; Margarita Peña, ensayista, investigadora y crítica litcraria: Entrelíneas, Vivir de nuevo, Alegoría y Auto sacramental; prólogos a Flores de Varia poesía (1577), a Mofarandel de los oráculos de Apolo y a México 1554, de Francisco Cervantes de Salazar. La primera y la tercera practican, asimismo, el periodismo litcrario. Participaron tambićn en la promoción generacional El Rehilete, Elsa de Llarena y Lourdes de la Garza.

Una cscritora como Rosario Castellanos (1925-1974) es ubicable en los apartados de poesía, novela, cuento, ensayo y tcatro, ya que practicó todos estos géneros. Su quchacer poćtico (Trayectoria del polvo, De la vigilia estéril, Livida luz) fuc recopilado bajo cl título Poesía no eres tú. Es, sin duda, una de las grandes 
poctisas mexicanas de este siglo, ducña de una conciencia lúcida ante la realidad que la acosa. Al igual que la mayoria de las poetisas del XX, rompe con los metros y escribe verso libre. De su amplia obra se desprenden poemas cardinales: "La lamentación de Dido" es una saga poética sobre el destino de la mujer dentro de la parcja, lograda a través de la mimetización Castellanos -Dido. "Kinsey Report" y "La jornada de la soltera" cjemplifican el tono de desesperación irónica, línicas de sus pocmas. Del segundo reproducimos una cstrofa:



Prosista que retrata críticamente la urdimbre de las relaciones humanas, cscribe rclatos: Ciudad real, Los convidados de agosto, Album de familia. Su obra novelística se apuntala en dos libros ya clásicos que grosso modo, se inscriben dentro de la novela indigenista, en el "ciclo de Chiapas": Balún Canán, novela con sustrato autobiográfico, y Oficio de Tinieblas, que relata la situación detonante de los oprimidos (los indígenas.y cl núcleo de las mujeres) en un lugar de Chiapas, durante la primera mitad del siglo. Escribió un libro de cnsayos: Mujer que sabe latin, y teatro, El eterno femenino, Tablero de damas. Por la calidad litcraria y trascendencia de su poesía y su prosa (testimoniales, de denuncia) es una de las autoras de este siglo que cuenta con una amplia difusión y con una exégesis abundante.

A lo largo del siglo XX la prosa es tan frecuentada por las escritoras como la poesía. María Enriqueta Camarillo de Pereyra vio la luz en 1872, y murió cntrado ya el XX. De sensibilidad romántica e influencias modernistas, más que por sus pocmas, es literariamente recordada por su prosa (relatos y novelas): Sorpresas de 
la vida, Lo irremediable, Jirón del mundo, y scis libros de lcciura: Rosas de la infancia, que nutricron la educación primaria de dos generaciones de mexicanos. Nellie Campobello (1909) dejó, en dos libros fundamentales: Cartucho y Las manos de mamá, la visión testimonial de la gesta revolucionaria presenciada, a través de los ojos propios y ajenos, por una niña de receptividad precoz, y narrada por una adulta dotada del don de la memoria. Su obra forma parte sustancial de la llamada "Novela de la Revolución".

La verdadera identidad de Asunción Izquierdo de Albiñana (1914-1978), se ocultó bajo diversos scudónimos: "Alba Sandoiz", "Pablo Maria Fonsalba", con los cuales firmó Andreida, Caos, La selva encantada (de ribetes autobiográficos), La ciudad sobre el lago, y Los extraordinarios. Atraída por los ambientes inusualcs y las situaciones humanas laberínticas, Los extraordinarios, que narra un crimen, está a punto de configurarse como novela policíaca, género que sólo empezará a encontrar expositoras femeninas en ćpocas recientes. Las "Agatha Christies" mexicanas, desafortunadamente, no han abundado.

Nacida en 1915, recién y merecidamentc homenajeada, a Josefina Vincens se la conoce fundamentalmente por El libro vacio, novela de personaje masculino, de plantcamientos ontológicos y cuestionamicntos existenciales que abordan el problema del creador ante la urgente necesidad de expresarse por medio de la escritura. Es una de las escritoras que han recibido el Premio Villaurrutia; en época ccrcana todavía publicó Los años falsos.

Elena Garro (1920), exiliada por propia voluntad desde hace largo tiempo en París, cs dramaturga y novelista. Los recuerdos del porvenir, novcla que oscila entre el realismo y lo onírico, lejanamente emparentada con la producción novelística de Aguslín Yáñez y de Juan Rulfo, recrea, en medio de atmósferas alucinantes y poéticas, la época postrevolucionaria. Es, sin duda, una de las mejores novelas escritas en México por una mujer. Ha frecuentado también el relato: La semana de colores y Andamos huyendo, Lola. Respecio a su obra dramática, de clla se ha dicho que "ligada al movimiento de teatro universitario que habría de conquistar la contemporaneidad de nuestro teatro, es creadora de un experimento dramático que consigue subsistir al simulacro fugaz del teatro del absurdo, y la consistencia de su intuición dramática la lleva a crear la primera propuesta de cpicidad teatral mexicana. Un argumento mudo resulta más clocuente para valorar su aportación: su obra gana con el tiempo y se convierte cn grave asignatura pendicnte de nucstra cscena"'. A Luisa Josefina IIernández

\footnotetext{
${ }^{1}$ Luis de Tavira, "Bajo cl signo de la diosa", en La mujer mexicana en el arte. México: Bancreser, 1987, p. 121 .
} 
(1928) se le conoce básicamente como autora dramática, pero su producción novelística marca la pauta de una obra que no se demora en la anécdota intrínsecamente fenemina, sino que intenta analizar, con austeridad, con sentido del humor, con iristeza sofrenada, la condición humana. El lugar donde crece la hierba, La plaza de puerto Santo, Los palacios desiertos, La cólera secreta, Aposiasía, son sus principales títulos. Sc ha dedicado, igualmente, a la traducción del inglés, del francés y del alemán. Respecto a su obra como dramaturga se considera que es "heredera del proyecto teórico de Usigli, que soñaba con la creación de una escucla mexicana de teatro, construyc una obra dramática rigurosamente cstructurada, que cataliza la crisis del realismo hacia una dimensión que vincula cl texto al desarrollo de una cstética actoral congruente y sistemática. Macstra de dramaturgos, cómplice de los directores de escena que realizan la renovación del lenguaje teatral, cl trabajo de Luisa Josefina Hernández rebasa $\mathrm{cl}$ ámbito dramatúrgico, para consistir en uno de los más sólidos fundamentos teóricos del discurso teatral de nuestros dias"”.

Inés Arredondo (1928), con La señal, se reveló como cuentista que recrea atmósfcras tensas, en las que aparentemente no pasa nada, cargadas de violencia interior. Logró un gran éxito de crílica, ratificado con Río subterráneo, y se ubicó en el que, muy libremente, podría llamarse "grupo de la Casa del Lago", de mediados de los sesenta, al cual pertenecicron escritores como Juan García Ponce, Huberto Batis y Juan Vicente Melo. Julieta Campos (1932), cubana de nacimiento, reside en México desde 1955. Traduce y escribe novelas y ensayo. Cabe mencionar dos títulos fundamentales en ambos géneros, respectivamente: Muerte por agua y La imagen en el espejo.

La prosa femenina se vuclve, en la segunda mitad del siglo $X X$, cada día más abundante. Como la escrita con anierioridad, parte generalmente de la autobiografía, de la definición del lugar que le toca ocupar a la mujer cn cl mundo, para llegar hasta la exploración de premisas universales. En lo primero se empareja con la pocsía de Guadalupe Dueñas (1920) y María Amparo Dávila (1928), cucntistas, aquélla, autora de Tiene la noche un árbol; ćsta, con Tiempo destrozado y Música concreta, obras cn las que altcrnan la subjetividad y la fantasía; son, junto con las novelistas, las precursoras de narradoras contemporáneas fecundas $\mathrm{en} \mathrm{el}$ quehacer literario: Esther Seligson (Tras la ventana un árbol, Luz de dos, Otros son los sueños, que obtuvo el Prcmio Villaurrutia, y la reciente Sed de mar); María Luisa Puga (Las posibilidades del odio, Pánico o peligro); Silvia Molina (La mañana debe seguir gris, también Premio Villaurrutia; Ascención Tun, Leyendo en

${ }^{2}$ Loc. cit. 
la torluga, La familia vino del norte); Aline Peterson (Sombra ella misma, Los colores ocullos). Cada una en sus respectivos diapasones, mancjando la reflexión o la ançcdota, escriben ficción en forma de cuento y novela.

Angeles Mastretta ha logrado gran éxito de público con Arráncame la vida, novela teñida de humor y de sarcasmo en relación al papel de la mujer dentro del matrimonio.

Angelina Muñiz introduce la temática procedente de la literatura española antigua cn la novela y cl relato: Morada interior, Tierra adentro, y obtuvo cl Premio Villaurrutia con IIuerto cerrado, II uerto sellado. Pertenece al grupo de autoras que como Espcjo, Peña, Margo Glantz, (Genealogías, La lengua en la mano), Mónica Deneymet, Eugenia Revueltas (José Revueltas en el banquillo de los acusados), Ana María Maqueo, combinan cl cjercicio de la litcratura, a veces en el género del ensayo, en el terreno de la crítica, con la cátedra universitaria.

Por lo que toca a escritoras vertidas de modo casi exclusivo hacia la creación dramática, hay que mencionar a Maruxa Vilalla, Marcela del Río, Margarita Urueta y Mireya Cueto, autora csta última de tcatro guiñol. Y entre las más jóvencs a Sabina Berman, autora que, de acuerdo con Luis de Tavira, hace concebir esperanzas de renovación dramática en cl ámbito de la escritura femenina ${ }^{3}$. No podemos cerrar este recuento sin mencionar a cscritoras - periodistas como María Luisa Mendoza (Contigo, conmigo, con nosotros tres); a Elena Ponialowska, dotada de una aguda conciencia social que se expresa en la crónica periodística y cn la novela (La noche de Tlatelolco, Ilasta no verte, Jesüs mí, La flor de Lis); y sin duda la más sobresalienic en ese géncro mixto: a Cristina Pacheco, (Sopita de fideos). Alaide Foppa, Elena Urrutia, (editoras, estas dos, de la publicación feminista Fem), Tita Valencia, Manou Dornbierer, Ana María Maqueo (Crimen de color oscuro), Malú Iluacuja, Martha Robles, Sara Sefcovich, Aralia López (Novela para una carta y la recientísima Sema, o las voces), que vierten una percepción propia y singular de la existencia en los moldes variados de la ficción, cl ensayo, la crónica, la crílica literaria, recurriendo al diálogo, al monólogo, al símbolo, a la imagen, al análisis textural. Como sus antecesoras, sus hermanas de los siglos XVI, XVII, XVIII, XIX, y al igual que las poctisas, las dramaturgas, se crigen, para utilizar la expresión de Emmanuel Carballo, y paralclamente a los escritorcs hombres, cn "protagonistas de la litcratura mexicana". Las escritoras de hoy inundan, con sus voces, el ámbito de casi un siglo derramando en el cotidiano y voluntario cjercicio de la escritura, una catarata, un torrente -imprescindible ya para enjuiciar cabalmente nuestra literatura-de, a vecesdifíciles, arduas palabras.

${ }^{3}$ Loc. cit. 
